\title{
Study of Positronium in Low-k Dielectric Films by Means of 2D-Angular Correlation Experiments at a High-Intensity Slow- Positron Beam
}

Th. Gessmann, M. P. Petkov, M. H. Weber, K. G. Lynn, K. P. Rodbell, P. Asoka-Kumar, W. Stoeffl, and R. H. Howell

Lawrence Livermore National Laboratory
This article was submitted to

$12^{\text {th }}$ International Conference on Positron Annihilation, Munich, Germany, August 6-12, 2000

\section{June 20, 2001}




\section{DISCLAIMER}

This document was prepared as an account of work sponsored by an agency of the United States Government. Neither the United States Government nor the University of California nor any of their employees, makes any warranty, express or implied, or assumes any legal liability or responsibility for the accuracy, completeness, or usefulness of any information, apparatus, product, or process disclosed, or represents that its use would not infringe privately owned rights. Reference herein to any specific commercial product, process, or service by trade name, trademark, manufacturer, or otherwise, does not necessarily constitute or imply its endorsement, recommendation, or favoring by the United States Government or the University of California. The views and opinions of authors expressed herein do not necessarily state or reflect those of the United States Government or the University of California, and shall not be used for advertising or product endorsement purposes.

This is a preprint of a paper intended for publication in a journal or proceedings. Since changes may be made before publication, this preprint is made available with the understanding that it will not be cited or reproduced without the permission of the author.

This report has been reproduced directly from the best available copy.

Available electronically at http://www.doc.gov/bridge

Available for a processing fee to U.S. Department of Energy

And its contractors in paper from

U.S. Department of Energy

Office of Scientific and Technical Information

P.O. Box 62

Oak Ridge, TN 37831-0062

Telephone: (865) 576-8401

Facsimile: (865) 576-5728

E-mail: reports@adonis.osti.gov

Available for the sale to the public from

U.S. Department of Commerce

National Technical Information Service

5285 Port Royal Road

Springfield, VA 22161

Telephone: (800) 553-6847

Facsimile: (703) 605-6900

E-mail: orders@ntis.fedworld.gov

Online ordering: http:/ / www.ntis.gov/ordering.htm

\section{OR}

Lawrence Livermore National Laboratory

Technical Information Department's Digital Library

http: / / www.llnl.gov/tid/Library.html 


\title{
Study of Positronium in Low-k Dielectric Films by Means of 2D-Angular Correlation Experiments at a High-Intensity Slow-Positron Beam
}

\author{
Th. Gessmann ${ }^{1}$, M.P. Petkov ${ }^{1}$, M.H. Weber ${ }^{1}$, K.G. Lynn ${ }^{1}$ \\ K.P. Rodbell ${ }^{2}$ \\ P. Asoka-Kumar ${ }^{3}$, W. Stoeffl $1^{3}$, R. H. Howell ${ }^{3}$ \\ ${ }^{1}$ Department of Physics, Washington State University, Pullman, Washington 99163, USA \\ ${ }^{2}$ IBM T. J. Watson Research Center, Yorktown Heights, New York 10598, USA \\ ${ }^{3}$ Department of Physics, Lawrence Livermore National Laboratory, \\ Livermore, California 94551, USA
}

Keywords: Slow positron beam, angular correlation , positronium, thermalization

\begin{abstract}
Depth-resolved measurements of the two-dimensional angular correlation of annihilation radiation (2D-ACAR) were performed at the high-intensity slow-positron beam of Lawrence Livermore National Laboratory. We studied the formation of positronium in thin films of methylsilsesquioxane (MSSQ) spin-on glass containing open-volume defects in the size of voids. Samples with different average void sizes were investigated and positronium formation could be found in all cases. The width of the angular correlation related to the annihilation of parapositronium increased with the void size indicating the annihilation of non-thermalized parapositronium.
\end{abstract}

Positron annihilation spectroscopy has been successfully applied to study the properties of so-called "low-k" materials with values of the relative dielectricity constant $k$ much smaller than the dielectric constant $k=4$ in solid silica [1,2,3,4]. These materials are currently being developed to decrease the $R C$-signal delay times in future miniaturized microelectronic devices. The value of the dielectric constant is lowered by introducing voids to produce porosity.

Films of polymerized organosilicates spun onto Si-substrates are good candidates for "low-k" materials. Voids are generated by curing a mixture of the prepolymer and a porogen at elevated temperatures. During the polymerization the porogen volatilizes resulting in low-k films containing a distribution of nanometer-sized pores. The average pore size is expected to increases with the porogen content of the mixture. Features like small film thicknesses and closed porosity make it difficult to investigate the pore charactersitics by techniques like gas absorption or Rutherford backscattering; on the other hand slow positron beam techniques are uniquely capable to extract information under these circumstances [5].

Depth-dependent Doppler-broadening measurements found uniform distributions of open-volume defects throughout films of hydrogen-silsesquioxane (HSSQ) and could established a correlation between the $S$-parameter and the value of the dielectric constant [2]; the effects of aging and oxidation on the film properties were also investigated [3]. Positron lifetime measurements studied positronium (Ps) formed in high fractions and annihilating inside the pores. Ortho-positronium (o-Ps) lifetimes close to the the vacuum lifetime were found indicating the escape of o-Ps through interconnected pores back to the sample surface [1]; pores size distributions for films with closed porosity could be deduced [4].

Measurements of the two-dimensional angular correlation of positron annihilation (2D-ACAR) have been successfully utilized to study the short-lived Ps-species para-positronium (p-Ps) 
annihilating in interfacial voids of $\mathrm{SiO}_{2}-\mathrm{Si}$ systems [6] or in porous silica [7]; in the present work we report on results obtained from beam 2D-ACAR measurements on methyl-silsesquioxane (MSSQ) low-k films.

The beam 2D-ACAR experiment is set up at Lawrence Livermore National Laboratory and uses positrons produced by pair-creation in the LINAC-facility. The initial LINAC-positron beam consists of $3 \mu \mathrm{s}$ pulses at a typical repetition rate of $300 \mathrm{~Hz}$. This pulsed beam is transformed to a quasi-continuous beam in a penning trap pulse stretcher [8]. The positrons released from the trap possess an average kinetic energy of about $20 \mathrm{eV}$ and are magnetically guided to the ACAR-target chamber. Here they can be accelerated to energies upto $30 \mathrm{keV}$ prior to being implanted into the sample. About $2 \times 10^{8} \mathrm{e}^{+} / \mathrm{s}$ hit the target within a beam spot of about $5 \mathrm{~mm}$ diameter. The emitted $511 \mathrm{keV}$-photons pass through UHV-windows and are detected by two Anger cameras with an active diameter of $470 \mathrm{~mm}$ each; the cameras are located $18 \mathrm{~m}$ away from each other with the target chamber in the middle. 2D-ACAR spectra containing about $1 \times 10^{6}$ counts were collected at typical coincidence countrates of about $200 \mathrm{cps}$.

The investigated low-k samples were produced with relative porogen contents 0.05 ("small pores") and 0.25 ("large pores") with respect to the volume of the prepolymerized mixture. 2D-ACAR spectra were taken at a beam energy $E=3 \mathrm{keV}$ corresponding to mean positron implantation depths in the middle of the films. The raw data normalized to the same number of total counts are shown in Fig. 1; a sharp peak in the central portion indicates p-Ps annihilation and could not be found in single-crystalline Si where no Ps is formed.

Fig. 2a shows the ratio between the two ACAR-spectra at $3 \mathrm{keV}$ and illustrates that the p-Ps peak for the sample with smaller pores is higher; as a measure of the peak width the Full Width at Half Maximum (FWHM) was obtained from the projections of the 2D-ACAR spectra on the $y$-axis (long-slit spectra); we found FWHM = (34 \pm 1$)$ channels (large pores) and FWHM $=(30 \pm 1)$ channels (small pores). This result is not consistent with annihilation of thermalized p-Ps since in such a case the FWHM should decrease with increasing pore size. We therefore suggest that the broader p-Ps peak connected with the larger pores is caused by a higher fraction of p-Ps annihilating from a non-thermalized state.

The thermalization process of p-Ps trapped in pores may be governed by collisions with pore walls; then the decrease of the number of collisions per p-Ps lifetime with increasing pore size results in longer p-Ps thermalization times $\tau_{\text {th }}$. A quantitative model is clearly required to extract values for $\tau_{\mathrm{th}}$; however; since the present indications for incomplete $\mathrm{p}$-Ps thermalization were obtained from a non time-resolving measurement $\tau_{\text {th }}$ should be comparable to the p-Ps lifetime.

Fig. $2 \mathrm{~b}$ shows a ratio of $2 \mathrm{D}$-ACAR spectra measured on the sample with small pores at two different beam energies $E=3 \mathrm{keV}$ ("bulk") and $E<0.3 \mathrm{keV}$ ("surface"). The data are consistent with an asymmetrical broadening of the surface spectrum with respect to the bulk spectrum in a momentum direction perpendicular to the sample surface possibly indicating the escape of p-Ps back into the vacuum. This could be a way to study pore interconnectedness since even in its short lifetime non-thermalized p-Ps might be able to diffuse back to the surface from regions deeper in the film.

In conclusion 2D-ACAR measurements on low-k films containing pores of two different average sizes showed evidence for the formation of p-Ps. The increased broadening of the p-Ps momentum distribution connected with the larger pores was interpreted as indication for p-Ps annihilation from a non-thermalized state with thermalization times comparable to the p-Ps lifetime.

The capability of the 2D-ACAR method to detect asymmetries in the momentum distribution might be used to study the escape of non-thermalized p-Ps from the sample through interconnected pores. 

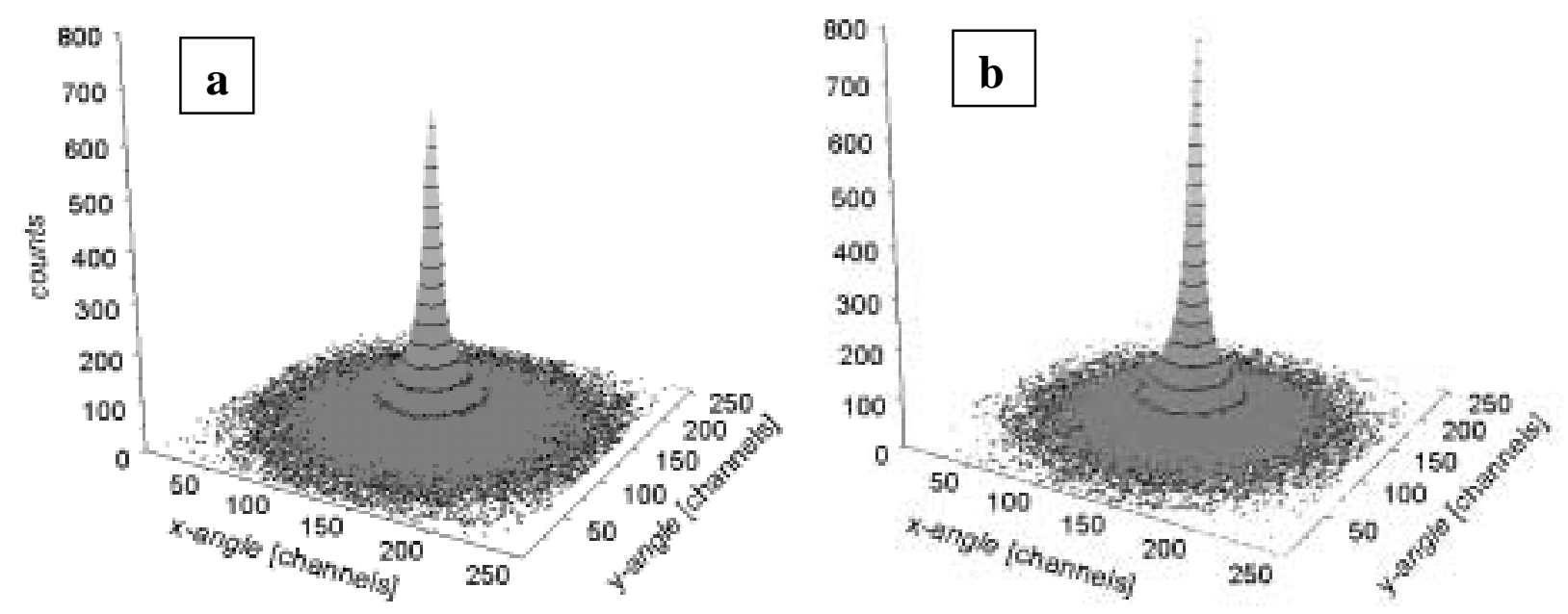

Figure 1 2D-ACAR spectra measured at a $E=3 \mathrm{keV}$ on two low-k samples containing large (a) and small (b) pores. The spectra are normalized to the same number of total counts.
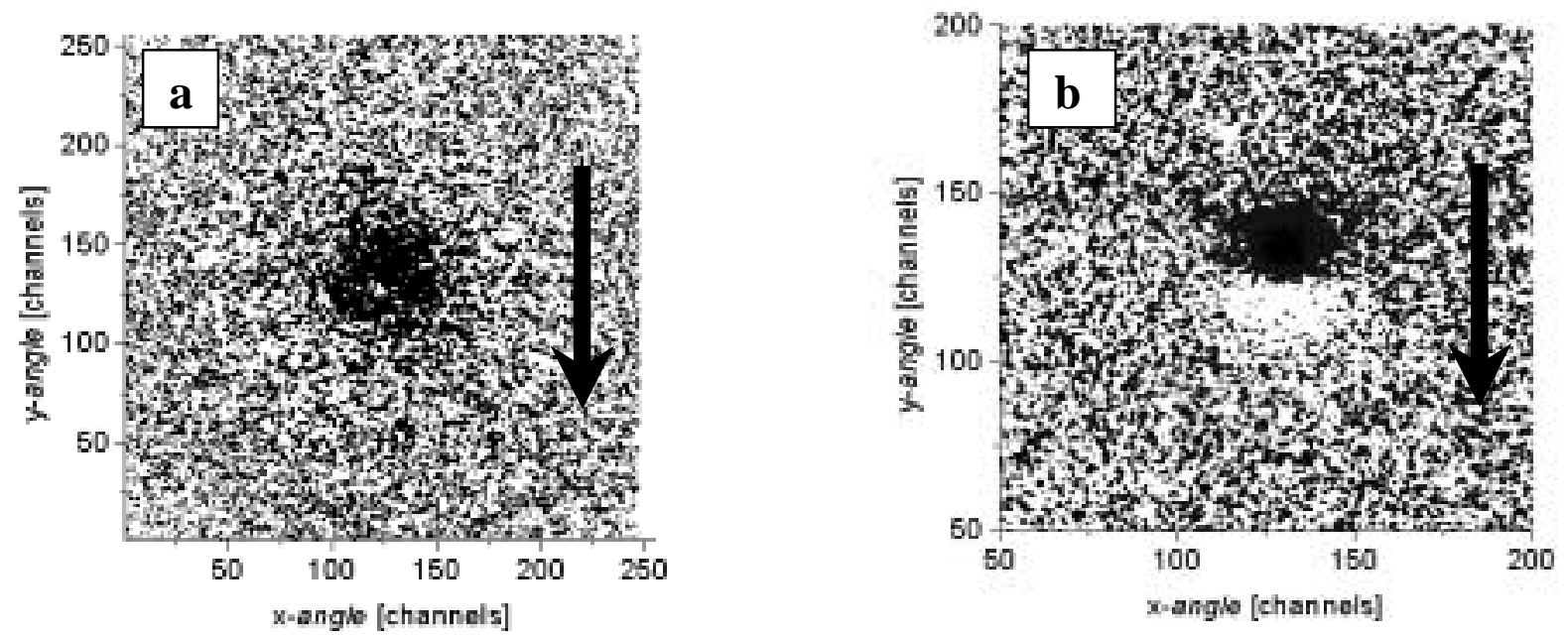

Figure 2 Ratios of 2D-ACAR spectra; (a) "small pores/large pores" (see Fig.1),

(b) "bulk / surface"; "Bulk" ("surface") denote spectra measured at $E=3 \mathrm{keV}(E<0.3 \mathrm{keV})$ on the sample with small pores. The arrows indicate the momentum direction towards the sample surface.

\section{References}

[1] D.W. Gidley, W.E. Frieze, T.L. Dull, A.F. Yee, E.T. Ryan and H.M. Ho, Phys. Rev. B 60 (1999), p. R1557.

[2] M.P. Petkov, M.H. Weber, K.G. Lynn, K.P. Rodbell, S. A.Cohen, Appl. Phys. Lett. 74 (1999), p. 2146.

[3] M.P. Petkov, M.H. Weber, K.G. Lynn, K.P. Rodbell, S. A.Cohen, J. Appl. Phys. 86 (1999), p. 3104.

[4] D.W. Gidley, W.E. Frieze, T.L. Dull, J. Sun, A.F. Yee, C.V. Nguyen and D.Y. Yoon, Appl. Phys. Lett. 76 (2000), p. 1282.

[5] P.J. Schultz and K.G. Lynn, Rev. Mod. Phys. 60 (1988) 701. 
[6] J.P. Peng, K.G. Lynn, P. Asoka-Kumar, D.P. Becker, D.R. Harshman, Phys. Rev. Lett. 76 (1996), p. 2157.

[7] M. Biasini, G. Ferro, M.A. Monge, G. di Francia, V. La Ferrara, J. Phys.: Condens. Matter 12 (2000), p. 5961.

[8] R.H. Howell, W. Stoeffl, P. Asoka-Kumar, P.A. Sterne, T.E. Cowan, J. Hartley, Mater. Sci. Forum 255-257 (1997), p. 644. 